\title{
The Association of Circulating MiR- 29b and Interleukin-6 with Subclinical Atherosclerosis
}

\author{
Yu-qing Huang ${ }^{a}$ Jie Li,b Ji-yan Chen ${ }^{a}$ Ying-ling Zhou ${ }^{a, b}$ An-ping Caia \\ Cheng Huang $^{\text {a }}$ Ying-qing Feng ${ }^{a}$
}

aDepartment of Cardiology, Guangdong Cardiovascular Institute, Guangdong Provincial Key Laboratory of Coronary Disease, Guangdong General Hospital, Guangdong Academy of Medical Sciences, School of Medicine, South China University of Technology, Guangzhou, 'bThe Jinwan Central Hospital of Zhuhai, Zhuhai Hospital of Guangdong General Hospital, Zhuhai, China

\section{Key Words}

Subclinical atherosclerosis $•$ MicroRNA $・$ MiR-29b $\bullet$ Interleukin-6

\begin{abstract}
Background/Aims: Although it is widely acknowledged that atherosclerosis is mainly a chronic inflammatory process, in which both miR-29b and interleukin-6 (IL-6) play multifaceted roles, the association between miR-29b and IL- 6 remains unknown. The aim of the present study was to explore the relationship between miR-29b and IL- 6 and to test whether circulating levels of miR-29b and IL-6 could predict atherosclerosis. Methods: A total of 170 participants were divided into two groups according to carotid intima-media thickness (CIMT): study group (CIMT $\geq 0.9 \mathrm{~mm}$ ) and control group (CIMT $<0.9 \mathrm{~mm}$ ). Levels of circulating miR-29b and IL- 6 were measured by quantitative real-time polymerase chain reaction (qRT-PCR) and enzyme-linked immunosorbent assay (ELISA), respectively. The association of miR-29b and IL-6 levels with CIMT was assessed using Spearman correlation analysis and multiple linear regression analysis. Results: The study group showed higher miR-29b levels (31.61 \pm 3.05 vs. $27.91 \pm 1.71 \mathrm{Ct}, p<0.001)$ and IL-6 levels $(3.40 \pm 0.67$ vs. $2.99 \pm 0.37 \mathrm{pg} / \mathrm{ml}, p<0.001)$, compared with the control group. CIMT was positively correlated with miR-29b $(r=0.587, p$ $<0.001)$ and IL-6 $(r=0.410, p<0.001)$, and miR-29b levels were also correlated with IL-6 ( $r$ $=0.242, p=0.001$ ). Multiple linear regression analysis also showed that CIMT was positively correlated with miR-29b and IL-6. After adjustment for age, body mass index, systolic blood pressure, total cholesterol and C-reactive protein, CIMT was still closely correlated with miR$29 \mathrm{~b}$ and IL-6. The combination of miR-29b and IL-6 (AUC $=0.901, p<0.001$ ) offered a better predictive index for atherosclerosis than either miR-29b (AUC $=0.867, p<0.001$ ) or IL-6 (AUC $=0.747, p<0.001$ ) alone. Conclusion: Circulating levels of miR-29b and IL-6 may be independently correlated with subclinical atherosclerosis, and may serve as novel biomarkers for the identification of atherosclerosis.




\section{Cellular Physiology Cell Physiol Biochem 2017;44:1537-1544 \begin{tabular}{ll|l} 
and Biochemistry & $\begin{array}{l}\text { DOI: 10.1159/000485649 } \\
\text { Published online: December 04, } 2017\end{array}$ & $\begin{array}{l}\text { (c) } 2017 \text { The Author(s). Published by S. Karger AG, Basel } \\
\text { www.karger.com/cpb }\end{array}$
\end{tabular}}

Huang et al.: MiR-29b is Related to Subclinical Atherosclerosis

\section{Introduction}

Atherosclerosis is the leading cause of cardiovascular disease (CVD), which is a major global public health problem in modern society [1]. Atherosclerosis is a condition in which an accumulation of cells, cholesterol and extracellular matrix causes thickening and hardening of the arterial wall [2]. Measurement of carotid intima-media thickness (CIMT) is routinely used to assess subclinical or clinical atherosclerosis and current evidence suggests that CIMT may indicate subclinical vascular disease that is amenable to preventative measures [3]. CIMT has been shown to predict cardiovascular risk in many large studies and is recommended for cardiovascular risk assessment in asymptomatic adults at intermediate risk of CVD [4]. It is now generally believed that atherosclerosis is mainly a chronic inflammatory process and increasing numbers of inflammatory mediators have been shown to play vital roles in the development of atherosclerosis [2].

Circulating microRNAs (miRNAs, miRs) are a type of non-coding RNA, about 21-25 nucleotides in length, which play vital roles in the modulation of gene expression at the post-transcriptional level [5]. It has been demonstrated that miRNAs contribute to a variety of biological processes, including angiogenesis or vascular remodeling, inflammation and oxidative stress [6]. miR-29b is a key circulating cytokine, which plays a multifaceted and vital role in atherosclerosis [7]. IL-6 is another cytokine that has previously been shown to have pro-inflammatory effects and to play an important role in propagating the downstream inflammatory response that underlies atherosclerosis [8].

There are, however, limited date on the relationship of IL- 6 and miR-29b with subclinical atherosclerosis and there are also no data on the levels of these biomarkers that would indicate subclinical atherosclerosis. In the present study, we sought to explore whether circulating levels of miR-29b and IL- 6 might represent potential non-invasive biomarkers of subclinical atherosclerosis.

\section{Materials and Methods}

Between May 2015 and September 2016, all the participants were enrolled consecutively in this study from the Guangdong General Hospital, Guangdong, China. A total of 170 participants were enrolled in this study: 85 patients ( 41 men; mean age, $50.48 \pm 5.78$ years) with CIMT $\geq 0.9 \mathrm{~mm}$ as our study group and 85 healthy volunteers (46 men; mean age, $51.22 \pm 5.42$ years) with CIMT $<0.9 \mathrm{~mm}$ as control group. The diagnosis of subclinical atherosclerosis was based on the value of CIMT, which was measured by carotid artery ultrasound. Participants with a history of coronary heart disease, cerebrovascular disease, diabetes mellitus, neck surgery, thyroid disease, heavy smoking or current use of certain medications (lipid-lowering, antiplatelet or antihypertensive drugs) were excluded. Among those exclusion criteria, cerebrovascular diseases were defined as a documented history of ischemic cerebrovascular event with or without sequelae, transient ischemic attack, or amaurosis fugax in the last 6 months. Healthy control subjects were invited from the community or outpatient. All of the participants underwent physical examination, office blood pressure measurement and CIMT measurement before the study. The CIMT of the common carotid artery was measured by ATL HDI 3000 ultrasound system (Advanced Technology Laboratories, Bothell, WA) equipped with a $5-\mathrm{MHz}$ linear array transducer as previously described [9]. A value $<0.9 \mathrm{~mm}$ was defined as normal CIMT and a value $\geq 0.9 \mathrm{~mm}$ was defined as increased CIMT. Subclinical atherosclerosis was defined as CIMT $\geq 0.9 \mathrm{~mm}$ [10]. The study was approved by the Medical Ethics Committee of Guangdong General Hospital and written informed consent was obtained from each patient prior to participation. The study was conducted in accordance with the Declaration of Helsinki.

\section{Sample Collection}

Samples were collected in the morning, prior to any treatment, from patients and healthy volunteers, following an overnight fast. Plasma was extracted by centrifuging blood samples at $3000 \mathrm{rpm}$ for $10 \mathrm{~min}$ at room temperature. Plasma samples were collected and divided into two aliquots, which were frozen separately at $-80^{\circ} \mathrm{C}$ before being used for analysis. Fasting blood glucose, serum lipid profiles, routine laboratory tests and renal function were measured using routine methods. 
Detection of miR-29b and IL-6

Total RNA, containing small RNAs, was extracted from plasma using TRIzol reagent (Invitrogen, Carlsbad, CA, USA) and purified using a mirVana miR Isolation Kit (Ambion, Austin, TX, USA), according to the manufacturer's protocol [11]. Plasma miRs were evaluated using the S-Poly (T) RT-qPCR method, as previously described, with miR-54 as the control [12]. The comparative cycle threshold (Ct) ( $\Delta \mathrm{Ct})$ was used to calculate the relative level of miRs. Mean Ct values and deviations between duplicates were calculated for all samples. $\Delta \mathrm{Ct}=\mathrm{Ct}(\mathrm{miR})$-Ct (miR-54). Plasma IL-6 levels were determined using enzyme-linked immunosorbent assay (ELISA) kits (QuantiGlo, R\&D Systems, Minneapolis, Minnesota), according to the manufacturer's instructions [13].

\section{Statistical analysis}

All continuous variables were expressed as mean \pm standard deviation. The Mann-Whitney U test or Student $t$ test was used to compare continuous variables between patients and controls. Correlations between continuous variables were assessed using the Spearman correlation coefficient. Multiple linear regression analysis was used to assess the relationship between CIMT and miR-29b or IL-6. Adjustments were made for age, body mass index, systolic blood pressure, total cholesterol and C-reactive protein (CRP). Statistical significance was defined as two-sided $p<0.05$. The predictive value of being diagnosed with atherosclerosis was evaluated using the receiver operating characteristic (ROC). Area under the ROC curve (AUC) was used as an accuracy index for evaluating the diagnostic performance of miR-29b and IL-6. Statistical analyses were performed using the Statistical Package for the Social Sciences (SPSS) version 22.0 (SPSS Inc., Chicago, IL, USA) and GraphPad Prism 5 (GraphPad Software, La Jolla, CA, USA).

\section{Results}

Clinical characteristics, plasma IL-6 concentration and miR-29b levels

Baseline date are shown in Table 1. At baseline, there were no statistically significant differences in age, sex, body mass index, fasting blood-glucose, total cholesterol, high-density lipoprotein cholesterol, low density lipoprotein cholesterol, triglycerides, glomerular filtration rate, diastolic blood pressure or heart rate between the groups. There were, however, statistically significant differences in CRP, systolic blood pressure, IL- 6 and miR-29b between the two groups. The study group showed higher miR-29b levels $(31.61 \pm 3.05$ vs. $27.91 \pm$ $1.71 \mathrm{Ct}, p<0.001)$ and IL-6 levels (3.40 \pm 0.67 vs. $2.99 \pm 0.37 \mathrm{pg} / \mathrm{ml}, p<0.001)$, compared with the control group (Fig. $1 \mathrm{~A}$ and 1B).

Correlation of miR-29b and IL-6 with CIMT

As shown in Table 2, CIMT was positively correlated with miR-29b $(\mathrm{r}=0.587$, $p<0.001)$, IL-6 ( $\mathrm{r}=0.410, p<0.001)$ and CRP ( $\mathrm{r}=0.447, p<0.001)$. miR-29b levels were positively correlated with IL-6 $(\mathrm{r}=$ 0.242, $p=0.001)$ and CRP ( $\mathrm{r}=0.356, p<$ $0.001)$. IL-6 levels were positively associated with CRP ( $\mathrm{r}=0.378, p<0.001)$. Multiple

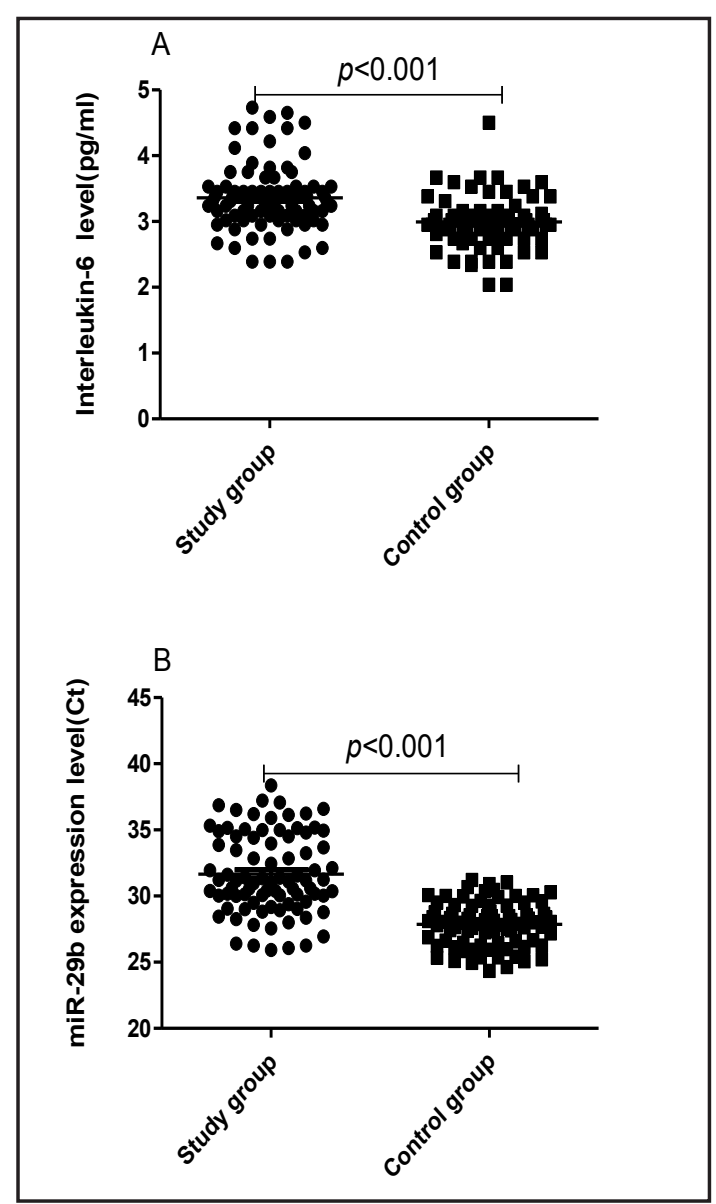

Fig. 1. A. Interleukin-6 levels in study group and control group; B. miR-29b expression levels in study group and control group. 
Table 1. Demographic, clinic and laboratory characteristics between groups. HDL-C, high-density lipoprotein cholesterol; LDL-C, low density lipoprotein cholesterol; GFR, glomerular filtration rate; CRP, C-reactive protein; DBP ,diastolic blood pressure; SBP, systolic blood pressure; IL-6,interleukin-6. Data are presented as the mean \pm standard deviation

\begin{tabular}{cccc}
\hline & $\begin{array}{c}\text { Study group } \\
(\mathrm{n}=85)\end{array}$ & $\begin{array}{c}\text { Control group } \\
(\mathrm{n}=85)\end{array}$ & $p$-value \\
\hline Males/females & $41 / 44$ & $46 / 39$ & 0.105 \\
Age (years) & $50.48 \pm 5.78$ & $51.22 \pm 5.42$ & 0.470 \\
Body mass index $\left(\mathrm{kg} / \mathrm{m}^{2}\right)$ & $26.54 \pm 3.42$ & $26.85 \pm 3.80$ & 0.411 \\
Total cholesterol $(\mathrm{mg} / \mathrm{dl})$ & $200.40 \pm 45.72$ & $192.94 \pm 38.00$ & 0.094 \\
HDL-C(mg/dl) & $50.46 \pm 13.15$ & $49.30 \pm 11.25$ & 0.711 \\
LDL-C(mg/dl) & $127.16 \pm 33.71$ & $123.41 \pm 33.52$ & 0.839 \\
Triglyceride $(\mathrm{mg} / \mathrm{dl})$ & $179.64 \pm 55.84$ & $153.86 \pm 59.74$ & 0.186 \\
GFR(ml/min/1.73m $\left.{ }^{2}\right)$ & $111.32 \pm 11.65$ & $111.06 \pm 13.85$ & 0.278 \\
Fasting blood-glucose(mmol/l) & $4.92 \pm 0.49$ & $5.01 \pm 0.53$ & 0.349 \\
Heart rate(beats/minute) & $74.69 \pm 10.82$ & $74.89 \pm 9.53$ & 0.125 \\
SBP(mm Hg) & $141.02 \pm 12.05$ & $136.55 \pm 15.66$ & $<0.001$ \\
DBP(mm Hg) & $84.95 \pm 8.49$ & $83.42 \pm 9.23$ & 0.328 \\
CRP(mg/l) & $17.34 \pm 5.48$ & $6.83 \pm 2.89$ & $<0.001$ \\
IL-6(pg/ml) & $3.40 \pm 0.67$ & $2.99 \pm 0.37$ & $<0.001$ \\
miR-29b expression level $(\mathrm{Ct})$ & $31.61 \pm 3.05$ & $27.91 \pm 1.71$ & $<0.001$ \\
\hline
\end{tabular}

Table 2. Relationship of miR-29b expression level with interleukin-6 and CIMT. CIMT; carotid intima-media thickness; IL-6, interleukin-6; CRP, C-reactive protein. The Spearman correlation coefficient was used for statistical analysis

\begin{tabular}{ccccccc}
\hline & miR-29b & \multicolumn{3}{c}{ CIMT } & \multicolumn{3}{c}{} \\
\hline & $\mathrm{r}$ & $p$ & $\mathrm{r}$ & $p$ & $\mathrm{r}$ & $p$ \\
miR-29b & & & 0.242 & 0.001 & 0.587 & $<0.001$ \\
IL-6 & 0.242 & 0.001 & & & 0.410 & $<0.001$ \\
CRP & 0.356 & $<0.001$ & 0.378 & $<0.001$ & 0.447 & $<0.001$ \\
\hline
\end{tabular}

Table 3. Relation of interleukin- 6 and miR-29b with subclinical atherosclerosis. IL-6, interleukin-6. Multivariate linear regression analysis was used for statistical analysis. Model1: It was a standard model, Model2: Age, BMI, SBP, TC, and CRP were adjusted

\begin{tabular}{ccccc}
\hline & & $\beta$ & $p$ & $95 \% \mathrm{CI}$ \\
\hline Model1 & miR-29b & 0.481 & $<0.001$ & $0.380,0.662$ \\
& IL-6 & 0.232 & $<0.001$ & $0.154,0.503$ \\
Model2 & miR-29b & 0.467 & $<0.001$ & $0.372,0.645$ \\
& IL-6 & 0.213 & $<0.001$ & $0.161,0.407$ \\
\hline
\end{tabular}




\section{Cellular Physiology Cell Physiol Biochem 2017;44:1537-1544 and Biochemistry Published $\begin{aligned} & \text { DOI: 10.1159/000485649 } \\ & \text { (c) } 2017 \text { The Author(s). Published by S. Karger AG, Basel } \\ & \text { www.karger.com/cpb }\end{aligned}$

linear regression also showed that CIMT was positively correlated with miR-29b $(\beta$ $=0.481,95 \%$ CI $0.380,0.662 ; p<0.001)$ and IL-6 $(\beta=0.232,95 \%$ CI 0.154, 0.503; $p<0.001)$. After adjustment for age, body mass index, systolic blood pressure, total cholesterol and CRP, CIMT was still closely correlated with miR-29b $(\beta=0.467,95 \%$ CI $0.372,0.645 ; p<0.001)$ and IL-6 $(\beta=$ $0.213,95 \%$ CI $0.161,0.407 ; p<0.001$ ).

Predictive value of $\mathrm{miR}-29 \mathrm{~b}$ and $I L-6$ for subclinical atherosclerosis

An ROC analysis was performed to determine the predictive values of miR-29b and IL-6 for subclinical atherosclerosis (Table 3 ). The combination of miR-29b and IL-6 (AUC $=0.901$, sensitivity $=95.2 \%$, specificity $=85.1 \%, p<0.001$ ) was a better predictor for atherosclerosis than either miR-29b (AUC $=0.867$, sensitivity $=92.2 \%$, specificity $=81.2 \%, p<$ 0.001 ) or IL-6 (AUC $=0.747$, sensitivity $=82.3 \%$, specificity $=67.1 \%, p<0.001$ ) alone (Fig. 2).

\section{Discussion}

Atherosclerotic diseases are now a major global public health problem and increased CIMT is a hallmark of atherosclerotic diseases [14]. In the present study, subclinical atherosclerosis patients had significantly higher miR-29b, IL-6 and CRP levels than healthy volunteers. CIMT was shown to be positively correlated with miR-29b, IL-6 and CRP; miR29b levels were positively correlated with IL-6 and CRP; and IL-6 levels were positively correlated with CRP. Importantly, after adjustments for age, body mass index, systolic blood pressure, total cholesterol and CRP, CIMT was still closely correlated with miR-29b and IL6. An important finding of the study is that either miR-29b or IL-6 would be a good new biomarker for the identification of subclinical atherosclerosis. The most significant and meaningful discovery of this study is that the combined AUC of miR-29b and IL- 6 is a better indicator of preclinical atherosclerosis than the AUC of either miR-29b or IL-6 alone.

It is widely acknowledged that atherosclerosis is a complex inflammatory process [2] and, recently, circulating miRNAs have been recognized as novel biomarkers and potential therapeutic targets for CVD, including atherosclerosis [15]. miR-29b, a key circulating cytokine, has been shown to play a multifaceted and vital role in atherosclerosis [7]. We have shown that miR-29b levels are closely correlated with CRP and CIMT. CRP is an important systemic inflammatory marker, which is widely used in the clinic [16] and which has been shown to be predictive for CVD [17]. miR-29b may thus also be a vital inflammatory marker that plays an important role in the development of subclinical or clinical atherosclerosis. miR-29b has also been reported to be associated with endothelial cell dysfunction [18]. Mott et al. [19] reported that miR-29b is an important endogenous regulator, which plays a role in endothelial cell apoptosis by inhibiting the anti-apoptotic gene, myeloid cell leukemia-1. Anke and his team also showed that miR-29b mediates the deposition of collagen and fibrosis via IL- 6 and tumor growth factor- $\beta$ [20]. miR-29b has also been suggested to suppress the proliferation and migration of vascular smooth muscle cells, possibly through inhibition of myeloid cell leukemia- 1 and matrix metalloproteinase-2, indicating that miR-29b may serve 


\section{Cellular Physiology Cell Physiol Biochem 2017;44:1537-1544

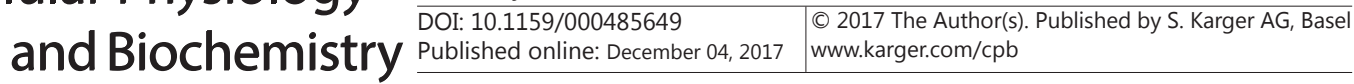 \\ Huang et al.: MiR-29b is Related to Subclinical Atherosclerosis}

as a valuable therapeutic tool to treat CVD, such as atherosclerosis [21].

Atherosclerosis as a common chronic process and many cytokines such as endothelial cells, smooth muscle cells or macrophages, could affect different stages in its progression [2, 22]. IL-6 is an important pro-inflammatory cytokine that may play a leading role in modulating the hepatic synthesis of CRP and fibrinogen [23]. IL-6 is also an upstream regulator that plays a central role in propagating the downstream inflammatory response responsible for atherosclerosis [2]. We found that levels of IL- 6 were positively correlated with CRP and CIMT and, after adjustment for age, body mass index, systolic blood pressure, total cholesterol and CRP, CIMT was still closely correlated with IL-6. This indicates that IL-6 is also a risk factor for subclinical or clinical atherosclerosis. Some previous cohort studies showed that patients with high levels of IL- 6 had an increased atherosclerotic burden and higher risk of major adverse cardiac events compared with individuals with lower levels of IL-6 [24, 25]. Interestingly, Bacchiega et al. found that the IL-6-blocking agent tocilizumab significantly reduced CRP concentrations, together with parameters of systemic inflammation [26]. IL-6 has many other functions, including activation of macrophages [27, 28] and stimulation of endothelial $[29,30]$ and vascular smooth muscle cells $[31,32]$. Although IL-6 and miR-29b both have a number of clear effects on different stages in the formation of atherosclerosis and are, individually, important markers for CVD, we have shown that that the combination of miR-29b and IL- 6 offers a better predictive marker for atherosclerosis than either miR-29b or IL- 6 alone. As indicated by our results, circulating levels of miR-29b or IL- 6 may serve as underlying and ponderable biomarkers for detecting subclinical or clinical atherosclerosis.

Several limitations should be taken into account when interpreting our results. Firstly, this was a cross-sectional study, which only shows a relationship but does not identify causality, so the results should not be used to draw causal conclusions. Secondly, the number of study subjects was relatively small, and multicenter, prospective studies with larger sample sizes are needed to confirm our results. Thirdly, the underlying mechanisms responsible for the correlation of circulating miR-29b and IL- 6 with CIMT were not elucidated. The potential roles of miR-29b and IL- 6 in atherosclerosis thus need to be fully elucidated by further basic research.

\section{Conclusion}

Our study showed that levels of circulating miR-29b and IL- 6 were increased in subjects with subclinical atherosclerosis, compared with healthy individuals. Circulating miR-29b and IL- 6 were independently correlated with CIMT. Increased levels of circulating miR-29b and IL-6 may serve as new biomarkers for subclinical or clinical atherosclerosis and may also be useful for clinical monitoring of the early stages in the development of atherosclerosis.

\section{Disclosure Statement}

The authors have no competing interests.

\section{Acknowledgements}

This work was supported by the grants from the Guangdong Natural Science Foundation (No. 2015A030313660), the Technology Project Foundation of Guangzhou (No. 2014y200140, No. 1563000381, No. 201604020018, No. 201604020186), the Technology Project Foundation of Guangdong Province (No. 2014B020212008) and the National Natural Science Foundation of China (No.81300230). 


\section{Cellular Physiology Cell Physiol Biochem 2017;44:1537-1544 \begin{tabular}{l|l|l} 
and Biochemistry Published online: December 04, 2017 & $\begin{array}{l}\text { (c) } 2017 \text { The Author(s). Published by S. Karger AG, Basel } \\
\text { www.karger.com/cpb }\end{array}$
\end{tabular}}

Huang et al.: MiR-29b is Related to Subclinical Atherosclerosis

\section{References}

1 Torres N, Guevara-Cruz M, Velazquez-Villegas LA, Tovar AR: Nutrition and Atherosclerosis. Arch Med Res $2015 ; 46: 408-426$.

- Hartman J, Frishman WH: Inflammation and atherosclerosis: a review of the role of interleukin- 6 in the development of atherosclerosis and the potential for targeted drug therapy. Cardiol Rev 2014;22:147-151.

3 Stein JH, Korcarz CE, Post WS: Use of carotid ultrasound to identify subclinical vascular disease and evaluate cardiovascular disease risk: summary and discussion of the American Society of Echocardiography consensus statement. Prev Cardiol 2009;12:34-38.

-4 Stein JH, Korcarz CE, Hurst RT, Lonn E, Kendall CB, Mohler ER, Najjar SS, Rembold CM, Post WS: Use of carotid ultrasound to identify subclinical vascular disease and evaluate cardiovascular disease risk: a consensus statement from the American Society of Echocardiography Carotid Intima-Media Thickness Task Force. Endorsed by the Society for Vascular Medicine. J Am Soc Echocardiogr 2008;21:93-111, 189-190.

-5 Mazloom H, Alizadeh S, Pasalar P, Esfahani EN, Meshkani R: Downregulated microRNA-155 expression in peripheral blood mononuclear cells of type 2 diabetic patients is not correlated with increased inflammatory cytokine production. Cytokine 2015;76:403-408.

6 Fang YC, Yeh CH: Role of microRNAs in Vascular Remodeling. Curr Mol Med 2015;15:684-696.

7 Kriegel AJ, Liu Y, Fang Y, Ding X, Liang M: The miR-29 family: genomics, cell biology, and relevance to renal and cardiovascular injury. Physiol Genomics 2012;44:237-244.

-8 Tvedt T, Ersvaer E, Tveita AA, Bruserud O: Interleukin-6 in Allogeneic Stem Cell Transplantation: Its Possible Importance for Immunoregulation and As a Therapeutic Target. Front Immunol 2017;8:667.

-9 Polak JF, Pencina MJ, Meisner A, Pencina KM, Brown LS, Wolf PA, D’Agostino RS: Associations of carotid artery intima-media thickness (IMT) with risk factors and prevalent cardiovascular disease: comparison of mean common carotid artery IMT with maximum internal carotid artery IMT. J Ultrasound Med 2010;29:1759-1768.

-10 Prandoni P, Ciammaichella M, Mumoli N, Zanatta N, Visona A, Avruscio G, Camporese G, Bucherini E, Bova C, Imberti D, Benedetti R, Rossetto V, Noventa F, Milan M: An association between residual vein thrombosis and subclinical atherosclerosis: Cross-sectional study. Thromb Res 2017;157:16-19.

11 Kang K, Zhang X, Liu H, Wang Z, Zhong J, Huang Z, Peng X, Zeng Y, Wang Y, Yang Y, Luo J, Gou D: A novel real-time PCR assay of microRNAs using S-Poly(T), a specific oligo(dT) reverse transcription primer with excellent sensitivity and specificity. PLoS One 2012;7:e48536.

-12 Baraniskin A, Nopel-Dunnebacke S, Ahrens M, Jensen SG, Zollner H, Maghnouj A, Wos A, Mayerle J, Munding J, Kost D, Reinacher-Schick A, Liffers S, Schroers R, Chromik AM, Meyer HE, Uhl W, Klein-Scory S, Weiss FU, Stephan C, Schwarte-Waldhoff I, Lerch MM, Tannapfel A, Schmiegel W, Andersen CL, Hahn SA: Circulating U2 small nuclear RNA fragments as a novel diagnostic biomarker for pancreatic and colorectal adenocarcinoma. Int J Cancer 2013;132:E48-E57.

13. Lee TM, Lin MS, Chang NC: Usefulness of C-reactive protein and interleukin- 6 as predictors of outcomes in patients with chronic obstructive pulmonary disease receiving pravastatin. Am J Cardiol 2008;101:530535.

14. Schoenhagen P, Tuzcu EM: Atherosclerosis imaging in progression/regression trials: surrogate marker or direct window into the atherosclerotic disease process? Arq Bras Cardiol 2008;91:385-398.

-15 Zuo K, Zhi K, Zhang X, Lu C, Wang S, Li M, He B: A dysregulated microRNA-26a/EphA2 axis impairs endothelial progenitor cell function via the p38 MAPK/VEGF pathway. Cell Physiol Biochem 2015;35:477488.

16 Singh TP, Morris DR, Smith S, Moxon JV, Golledge J: Systematic Review and Meta-Analysis of the Association Between C-Reactive Protein and Major Cardiovascular Events in Patients with Peripheral Artery Disease. Eur J Vasc Endovasc Surg 2017;54:220-233.

17 Kaptoge S, Di Angelantonio E, Lowe G, Pepys MB, Thompson SG, Collins R, Danesh J: C-reactive protein concentration and risk of coronary heart disease, stroke, and mortality: an individual participant metaanalysis. Lancet 2010;375:132-140.

18 Silambarasan M, Tan JR, Karolina DS, Armugam A, Kaur C, Jeyaseelan K: MicroRNAs in Hyperglycemia Induced Endothelial Cell Dysfunction. Int J Mol Sci 2016;17:518. 


\section{Cellular Physiology Cell Physiol Biochem 2017;44:1537-1544 \begin{tabular}{l|l|l|}
\hline DOI: 10.1159/000485649 & $\begin{array}{l}\text { C) } 2017 \text { The Author(s). Published by S. Karger AG, Basel } \\
\text { www.karger.com/cpb }\end{array}$ \\
\hline
\end{tabular} \\ Huang et al.: MiR-29b is Related to Subclinical Atherosclerosis}

19 Mott JL, Kobayashi S, Bronk SF, Gores GJ: mir-29 regulates Mcl-1 protein expression and apoptosis. Oncogene 2007;26:6133-6140.

20 Nijhuis A, Curciarello R, Mehta S, Feakins R, Bishop CL, Lindsay JO, Silver A: MCL-1 is modulated in Crohn's disease fibrosis by miR-29b via IL-6 and IL-8. Cell Tissue Res 2017;368:325-335.

-21 Lee J, Lim S, Song BW, Cha MJ, Ham O, Lee SY, Lee C, Park JH, Bae Y, Seo HH, Seung M, Choi E, Hwang KC: MicroRNA-29b inhibits migration and proliferation of vascular smooth muscle cells in neointimal formation. J Cell Biochem 2015;116:598-608.

-22 Song CL, Wang JP, Xue X, Liu N, Zhang XH, Zhao Z, Liu JG, Zhang CP, Piao ZH, Liu Y, Yang YB: Effect of Circular ANRIL on the Inflammatory Response of Vascular Endothelial Cells in a Rat Model of Coronary Atherosclerosis. Cell Physiol Biochem 2017;42:1202-1212.

-23 Yudkin JS, Kumari M, Humphries SE, Mohamed-Ali V: Inflammation, obesity, stress and coronary heart disease: is interleukin-6 the link? Atherosclerosis 2000;148:209-214.

24 Zhao L, Wang X, Yang Y: Association between interleukin-6 and the risk of cardiac events measured by coronary computed tomography angiography. Int J Cardiovasc Imaging 2017;33:1237-1244.

25 Ridker PM, Rifai N, Stampfer MJ, Hennekens CH: Plasma concentration of interleukin-6 and the risk of future myocardial infarction among apparently healthy men. Circulation 2000;101:1767-1772.

26 Bacchiega BC, Bacchiega AB, Usnayo MJ, Bedirian R, Singh G, Pinheiro GD: Interleukin 6 Inhibition and Coronary Artery Disease in a High-Risk Population: A Prospective Community-Based Clinical Study. J Am Heart Assoc 2017;6.

27 Hassanpour P, Amirfarhangi A, Hosseini-Fard SR, Yarnazari A, Najafi M: Interleukin 6 may be related to indoleamine 2, 3-dioxygense function in M2 macrophages treated with small dense LDL particles. Gene 2017;626:442-446.

28 Zhou Y, Zhang T, Wang X, Wei X, Chen Y, Guo L, Zhang J, Wang C: Curcumin Modulates Macrophage Polarization Through the Inhibition of the Toll-Like Receptor 4 Expression and its Signaling Pathways. Cell Physiol Biochem 2015;36:631-641.

29 Varejckova M, Gallardo-Vara E, Vicen M, Vitverova B, Fikrova P, Dolezelova E, Rathouska J, Prasnicka A, Blazickova K, Micuda S, Bernabeu C, Nemeckova I, Nachtigal P: Soluble endoglin modulates the proinflammatory mediators NF-kappaB and IL-6 in cultured human endothelial cells. Life Sci 2017;175:52-60.

-30 Sosinska P, Baum E, Mackowiak B, Maj M, Suminska-Jasinska K, Staniszewski R, Breborowicz A: Sulodexide Reduces the Proinflammatory Effect of Serum from Patients with Peripheral Artery Disease in Human Arterial Endothelial Cells. Cell Physiol Biochem 2016;40:1005-1012.

-31 Outzen EM, Zaki M, Mehryar R, Abdolalizadeh B, Sajid W, Boonen HC, Sams A, Sheykhzade M: Lipopolysaccharides, but not Angiotensin ll, Induces Direct Pro-lnflammatory Effects in Cultured Mouse Arteries and Human Endothelial and Vascular Smooth Muscle Cells. Basic Clin Pharmacol Toxicol 2017;120:335-347.

-32 Xu X, He M, Liu T, Zeng Y, Zhang W: Effect of Salusin-beta on Peroxisome Proliferator-Activated Receptor Gamma Gene Expression in Vascular Smooth Muscle Cells and its Possible Mechanism. Cell Physiol Biochem 2015;36:2466-2479. 